\title{
Governamentalidade e Soberania na Fronteira Brasil-Bolívia: Segurança Nacional e Saúde Pública como Dispositivos de Poder
}

\author{
Gustavo Villela Lima da Costa
}

Faculdade de Formação de Professores, Universidade do Estado do Rio de Janeiro (UERJ), Rio de Janeiro, RJ, Brasil. E-mail: gustavovillelalimadacosta@gmail.com

\begin{abstract}
o longo do tempo de pesquisa na cidade de Corumbá, em Mato Grosso do Sul, entre 2009 e $2013^{1}$, observamos que o Estado brasileiro (do nível federal aos municipais) atua principalmente em duas áreas específicas nas políticas públicas para a fronteira: segurança e saúde. Para articularmos os elementos centrais dessa governamentalidade $e^{2}$ fronteiriça em torno dos dispositivos de segurança e de saúde, entendemos que a ubiquidade do nacionalismo estatal tende a construir e a reproduzir a fronteira de modo binário (tanto territorialmente, "lá e aqui", quanto socialmente, "nós e eles"), a partir de representações que constroem simbolicamente essas regiões como lugares de perigo, dos crimes transfronteiriços, do contágio com o outro, e de possível contaminação física, e mesmo cultural, com o que vem do "exterior".
\end{abstract}

Essa governamentalidade estatal fronteiriça está, portanto, baseada tanto na soberania territorial e política do Estado (que se exerce de modo explícito, principalmente nas políticas de segurança e do monopólio da violência física, como veremos na primeira seção do artigo), quanto numa soberania nacional e cultural, que constrói e reproduz uma fronteira moral e social, como observaremos nas políticas de saúde na região, na segunda parte do texto (cuja violência simbólica se apresenta de modo muito mais eufemizado e tácito do que aquela do aparato de segurança). Destaca-se a existência de um ethos militar construído ao longo da própria história da cidade de Corumbá, fundada no século

DADOS - Revista de Ciências Sociais, Rio de Janeiro, vol. 61, non2, 2018, pp. 373 a 404.

http://dx.doi.org/10.1590/001152582018156

373 
XVIII como posto avançado militar, sendo ocupada pelos paraguaios durante a guerra da Tríplice Aliança, no século XIX, e mantendo-se, desde então, como um importante polo das Forças Armadas (principalmente da Marinha e do Exército) que reifica cotidianamente a ideia da fronteira como limite e "zona de segurança nacional", como uma região a ser tutelada pelas Forças Armadas.

A partir desses pressupostos, procuraremos analisar quais são os efeitos sociais dessa atuação do Estado na cidade de Corumbá, que incide principalmente sobre os atores sociais que dependem do cruzamento diário da fronteira para sobreviver. Essa construção do "outro" como ameaça também se manifesta nas questões de saúde e nos direitos sociais, vistos como se estivessem sob disputa e suspeição. Tais questões nos permitem observar as relações assimétricas entre a lógica da soberania estatal e a lógica dos moradores fronteiriços. Essa assimetria de poder é um dos principais fatores de conflitos e exclusão social na fronteira, assim como parte importante da construção social de sujeitos e identidades.

Para realizar esta investigação, partimos da observação dos dispositi$\operatorname{vos}^{3}$ de poder em torno da segurança nacional e da saúde pública como focos de análise a partir das seguintes fontes de pesquisa: em níveis nacional e estadual, utilizaremos como fontes a publicação em decreto de uma Estratégia de Defesa Nacional, o Plano Estratégico de Fronteiras, e também o impacto da criação do Gabinete Integrado de Gestão Fronteiriça (GGIFRON). Em âmbito local, observamos etnograficamente alguns eventos e situações sociais na fronteira: o fechamento de pontos de comércio informal na cidade (envolvendo a Polícia Federal e as Forças Armadas em ações conjuntas), as revistas policiais (com a presença cada vez maior da Força Nacional) em ônibus que fazem o trajeto de Campo Grande a Corumbá, e a utilização do hospital municipal por parte dos bolivianos e seus descendentes, especialmente na maternidade de Corumbá. Além disso, entre 2009 e 2013 foi possível observar in loco algumas operações sanitárias binacionais de controle de enfermidades colocadas em prática na região. Os jornais da cidade, principalmente o Diário Corumbaense e o Correio de Corumbá, assim como sítios eletrônicos do governo, também são fontes importantes para este trabalho enquanto elementos e enunciados constituintes desses dispositivos na fronteira, permitindo, assim, a análise das entrevistas de autoridades e da repercussão pública de alguns eventos aqui descritos. Além disso, ao longo de mais de quatro anos na cidade, acompanha- 
mos algumas reuniões públicas sobre segurança, entrevistamos policiais e militares e, também, agentes da secretaria de saúde e do meio ambiente.

Esse jogo de escalas é absolutamente imprescindível para a compreensão da vida social na fronteira, em que conjunturas internacionais e globais, políticas federais e estaduais, além das articulações municipais, intersecionam-se com a vida nas ruas, com o trabalho cotidiano de pessoas e grupos que utilizam a fronteira como um recurso social e econômico e, ali, constroem distintos sentidos de pertencimento.

Uma das questões principais do texto é compreender como se coloca a força física e simbólica do Estado nacional, que, de um lado, mantém como um de seus principais objetivos, a gestão e o controle de seu território e de suas fronteiras; e, de outro, a tutela de sua população e de sua cultura, exercida por uma "pedagogia" e uma gramática nacionalistas que criam e reproduzem fronteiras morais e sociais. É por essa razão que procuraremos, a partir da leitura de Agamben (2002), trabalhar com as interseções do modelo jurídico-institucional de poder (da soberania estatal, do "Estado territorial") e o modelo biopolítico de poder (governo da população, administração da vida biológica, do "Estado de população") para compreender as formas de dominação e o campo de disputas na fronteira.

\section{FRONTEIRA, PERIGO E CONTÁGIO: LOCAIS DE EXCEÇÃO?}

A cidade de Corumbá, fundada em 1778, está situada na fronteira do Brasil com a Bolívia a partir do município vizinho de Puerto Quijarro, possui em torno de 100 mil habitantes (IBGE, 2010) e tem no comércio uma de suas principais atividades econômicas, junto da pecuária e da mineração. Tradicionalmente, o comércio sempre foi uma atividade econômica importante na cidade, em função do porto no rio Paraguai, que é navegável até a cidade de Buenos Aires, na Argentina. Como a cidade está situada no meio do "corredor bioceânico", entre os portos de Arica, no Chile, e o de Santos, no Brasil, são inúmeras as atividades comerciais que aí se desenvolvem, seja a partir dos grandes exportadores de soja, minério e gás natural, por exemplo, seja a partir dos pequenos comerciantes que fazem sua vida nessa fronteira. Existe, na cidade, um intenso fluxo de caminhões e um grande número de transportadoras que trabalham com esse comércio binacional. Todo um mercado ilegal 
movimenta também uma série de atores sociais e tem grande importância na economia geral da cidade.

Nessa fronteira há uma conurbação de quatro cidades que, juntas, têm em torno de 160 mil habitantes: Corumbá e Ladário, no lado brasileiro, e Puerto Quijarro e Puerto Suarez, no lado boliviano. Outra característica importante da região é a sua distância de grandes centros urbanos como Santa Cruz de la Sierra (aproximadamente 600 km) e Campo Grande $(450 \mathrm{~km})$. Miranda (MS), a cidade seguinte depois da fronteira, fica a cerca de $200 \mathrm{~km}$ de Corumbá, e entre as duas cidades estão as terras alagáveis do Pantanal. A cidade de Corumbá se encontra em uma área de fronteira seca (na verdade, há uma pequena ponte sobre um riacho, entre os dois países), o que favorece o trânsito entre as duas cidades vizinhas, que é praticamente livre para os moradores fronteiriços, não sendo exigidos os documentos dos viajantes que pretendem entrar no Brasil ou Bolívia que precisam carimbar seus vistos na Polícias Federais dos respectivos países. $\mathrm{O}$ trânsito entre as duas cidades é intenso, em função do comércio e das relações de trabalho e sociais que aí se estabelecem.

Diante desse fluxo intenso e da proximidade com o país vizinho, observamos, a partir de pesquisas anteriores, um conjunto de representações negativas e discursos preconceituosos sobre os bolivianos na fronteira, em Corumbá, que os apresenta como "sujos", "enfermos", "perigosos", "preguiçosos" etc., assim como a Bolívia é representada como uma terra "sem lei", "sem ordem", "pobre", "atrasada", "governada por um índio", como se estivesse num degrau inferior da escala evolutiva e "civilizatória" em relação ao Brasil. De modo muito semelhante às pesquisas que realizamos em Corumbá (2015), o trabalho de Olivar, Cunha e Rosa (2015) também conclui que as desigualdades e hierarquizações em torno da nacionalidade e da etnia, tratam a presença peruana, na tríplice fronteira Brasil-Peru-Colômbia, em Tabatinga, como desqualificada, "invasora, malandra, nojenta, perigosa, pouco confiável, ou como vulnerável" (ibidem:125) A construção desses dispositivos de desigualdade é muito semelhante àquela que identificamos em nossas pesquisas sobre a condição dos bolivianos e seus descendentes em Corumbá (Costa, 2015). Essas representações negativas a respeito dos peruanos na Amazônia, e a ideia de um Brasil hegemônico (de superioridade dos brasileiros em relação aos peruanos), de acordo com aqueles autores, é bastante generalizada e atravessa desde discursos e práticas do cotidiano das pessoas na fronteira até políticas 
públicas e a atividade de agentes estatais como um princípio social de fronteirização (de reificação das diferenças hierarquizadas) que se "atualiza também no âmbito do Estado na sua capilaridade" (Olivar, Cunha e Rosa, 2015: 136). Esses processos de construção e reprodução da alteridade são estudados por Briones e Del Cairo, entendidos como "práticas de fronteirização" que são definidas como "las diversas maneras en que colectivos sociales marcan un adentro y un afuera, que encuentran un correlato en la diferenciación nosotros/otros" (Briones e Del Cairo, 2015:15).

Lois e Cairo (2011), por sua vez, entendem que as fronteiras, enquanto representações sociais, estão em constante produção e recriação, tanto em termos materiais quanto discursivos e práticos, ou seja, os processos de fronteirização estão em constante mudança, o que nos permite pensar as fronteiras para além dos limites estáveis e monolíticos dos Estados, e incluir as dinâmicas das populações locais. De acordo com esses autores, essas práticas de fronteirização são fundamentais para entender as dinâmicas de poder e as relações dialéticas entre Estados e população na construção do espaço fronteiriço, e também, em situá-las num tempo histórico em constante movimento que reelabora constantemente as ordens e desordens em um constante processo de materialização (Lois e Del Cairo, 2011:13).

De modo semelhante, Grimson (2003) está atento aos processos históricos, que reforçam a ideia da fronteira como espaço em construção, liminar, o que é fundamental para entender as dinâmicas de fronteirização designadas como:

los procesos históricos a través de los cuales los diversos elementos de la frontera son construídos por poderes centrales y por poblaciones locales. El concepto pretende enfatizar que, desde el punto de vista sociocultural, la frontera nunca es un dato fijo, sino un objeto inacabado e inestable. (Grimson, 2003:43)

Para Van Houtum e Naerssen (2002), por sua vez, o conceito de fronteirização (bordering) nos permite pensar os processos de "alterização" (othering), principalmente nas práticas de ordenamento do território e da diferenciação discursiva estabelecida entre "nós e eles" que se reflete no cotidiano, nos pequenos controles diários, observáveis empiricamente nas estratégias territoriais de "fronteirização, ordenamento e alterização". Essas estratégias são postas em prática pelos Estados para controlar a mobilidade, o fluxo econômico, e geram políticas de inclu- 
são e exclusão (quem tem direitos na fronteira?) sob a moldura dos processos específicos de construção das nações, que podem chegar, segundo os autores, a casos extremos de limpeza étnica e eliminação do "outro". Assim, uma das questões com as quais dialogamos diretamente com esses autores é aquela chamada por eles de "paradoxo dos processos de fronteirização" que, ao mesmo tempo em que negam a diferença e procuram apagar as ambiguidades sociais (nos processos de homogeneização nacional e cultural, por exemplo), acabam por construir e reproduzir novas alteridades e diferenças latentes nesses territórios.

Ao contrário dos discursos estatais, partimos do pressuposto de que a fronteira é um espaço em movimento, isto é, um espaço vivo e vivido, construído pelos seus moradores no constante processo de fronteirização da vida social. Tal perspectiva teórica nos permite ir além do dogma da soberania dos Estados nacionais e da ideia de fronteira como limite absoluto e área de segurança nacional. Do ponto de vista etnográfico, é preciso pensar a fronteira como zona "liminar", em permanente construção, vivenciada como uma "margem" com certa autonomia e poder, ao mesmo tempo em que é objeto de controle. Van Gennep, desde seus estudos clássicos, já afirmava que, durante a passagem ritual entre dois territórios ou entre status e posições sociais, existe uma região ou condição, a qual designa com o nome de "margem", que adquire, em determinadas ocasiões, certa autonomia, situada, liminarmente, entre dois mundos (ver Van Gennep, 1978). É preciso destacar que "fronteira" e "margem" não são entendidas, aqui, como sinônimos. A fronteira, neste trabalho, é mais uma categoria territorial estatal e nosso locus de pesquisa do que propriamente um conceito. Nesse sentido, propomos pensar a fronteira como uma "margem" do Estado que não se refere necessariamente a um determinado espaço físico ou geográfico, transcendendo-os (ver Das e Poole, 2008). As margens do Estado se configuram, fundamentalmente, a partir de um "modus operandi acionado e praticado pela burocracia estatal sobre populações, grupos ou corpos, no transcurso do processo de gestão de determinado território" (Palermo, 2015:61). O estudo dessas operações de vigilância na fronteira, não apenas a partir de grandes operações policiais, mas principalmente pelas revistas corriqueiras e cotidianas, pode revelar mecanismos de atuação do poder nos locais onde é implantado, em sua escala menor e onde produz efeitos reais. Os postos de controle, as operações de vigilância e as revistas policiais demandam certos procedimentos disciplinares que são incorporados 
também pelos moradores que cruzam a fronteira diariamente, impondo normas e padrões, gestos, olhares e comportamentos. O poder soberano exercido pelo Estado não se impõe somente sobre o território, mas também é exercido em sua face disciplinar sobre os corpos e sobre os comportamentos.

Leach (1995) contribui para nosso debate sobre a liminaridade das margens ao demonstrar como os indivíduos podem pertencer, ao mesmo tempo, a mais de uma estrutura social e a uma cultura, atravessando fronteiras físicas e simbólicas, de acordo com as circunstâncias (possuindo, portanto, múltiplas identidades). Esses sistemas ideais, dos quais a nacionalidade e os valores do Estado-nação são exemplos, apresentam-se muitas vezes a esses atores sociais como alternativas ou contradições no esquema de valores pelo qual ordenam suas vidas. Os conceitos de cultura ou de identidade nacionais ocultariam essas ambiguidades e tenderiam a essencializar esses modelos ideais que, na fronteira, giram em torno de categorias identitárias da nacionalidade, dos valores morais "nacionais", da cultura "brasileira" ou cultura "boliviana"; ou seja, essas categorias identitárias se apresentam em discursos calcados na figura do Estado-nação com uma rigidez e simetria que não se verificam empiricamente na vida social.

Afirmamos isso porque, apesar da nacionalidade ser uma categoria estruturante na região, as pessoas na fronteira subvertem essa lógica e esses discursos hegemônicos a partir de suas práticas sociais cotidianas que escapam ao controle estatal, como o comércio, a circulação de pessoas e mercadorias, o acesso a benefícios sociais, a opção pelo nascimento de filhos do outro lado da fronteira, os casamentos, amizades, festividades, a culinária etc., que tornam extremamente complexos os processos de construção de identidades nas regiões de fronteira.

Uma cena observada em Corumbá, no deslocamento até a fronteira, demonstra essa complexa relação entre nascimento, identidade, cultura, além dos direitos e deveres em relação ao Estado. Dois soldados do Exército brasileiro, fardados, conversavam em castelhano sobre assuntos diversos, no ônibus urbano "Fronteira", que vai do centro de Corumbá até bem próximo à linha de fronteira, saindo do quartel para suas casas em Puerto Quijarro. A farda do Exército e o serviço militar obrigatório, um dos maiores símbolos do pertencimento à nação, convivendo com o uso de uma língua estrangeira e a moradia em um outro 
país (subversão de dois símbolos "sagrados" do Estado-nação: a língua e o território).

Os moradores fronteiriços rompem, em várias situações, com a continuidade entre nascimento e nacionalidade, e colocam em xeque a "ficção originária da soberania moderna do Estado-nação", nos termos de Agamben (2002:138). De acordo com este autor, a estrutura política dos Estados nacionais se baseia no nexo entre três elementos: um território (uma localização específica), um ordenamento (o Estado e suas leis) e o nascimento (inscrição da vida, nascimento e nação). É preciso destacar que os bolivianos e seus descendentes não estão desprovidos de direitos na fronteira, mas há sempre a possibilidade de suspensão de acordos (formais ou informais) e sua cidadania tem sempre que ser conquistada, construída e justificada sob suspeição. Além disso, apenas os cidadãos que possuem dupla nacionalidade ou documentos de residência no lado brasileiro podem votar e participar da vida política (municipal, estadual e federal). Desse modo, como grande parte dos bolivianos que vive em Corumbá não vota, não constitui um nicho eleitoral para políticos locais que, apenas raramente, incorporam em seus programas as reivindicações por direitos dos bolivianos, o que contribui para o silenciamento de suas demandas. É como se os bolivianos, embora vivendo na cidade de Corumbá, não fizessem parte dela.

O diálogo com esses autores que pensam os processos de fronteirização, nos permite compreender como se articulam representações de longa duração e práticas do exercício dos micropoderes no cotidiano, e as relações dialéticas entre populações fronteiriças e o poder central. $\mathrm{O}$ foco deste artigo, entretanto, é tentar compreender aspectos centrais de uma governamentalidade fronteiriça e não as diversas estratégias de sobrevivência e resistência a esses dispositivos por parte da população local, já que tais assuntos já foram abordados em outros trabalhos que realizamos, alguns em parceria com colegas de pesquisa, seja na atuação dos taxistas na fronteira (Costa, 2014b), dos camelôs (idem, 2013b; 2014a), e nas matrículas nas escolas no lado brasileiro (idem, 2016). Dessa forma, entendemos que, embora as análises dos processos de fronteirização procurem superar a representação da fronteira em termos puramente binários (ou seja, apenas como regiões situadas entre Estados nacionais, entre "nós $x$ eles") e tentem dar conta das dinâmicas sociais a partir dos moradores da fronteira, a governamentalidade fronteiriça, em seus efeitos práticos, acaba reproduzindo e tentando impor esses binarismos calcados no dogma da soberania territorial nacional, 
estabelecendo conflitos entre o caráter móvel e fluído da fronteira e a concepção monolítica estatal.

Essa vida cotidiana da fronteira, que sempre demandou controles específicos, vem se reconfigurando, fruto das recentes políticas nacionais de fronteira no Brasil, principalmente após o ano de 2011, quando é posto em prática o Plano Estratégico de Fronteiras. Essa nova política de segurança nas fronteiras tem efeitos sociais no cotidiano das pessoas que vivem nessas regiões, e que transcendem os planos e objetivos propostos pelo Estado. A cidade de Corumbá tem recebido aportes financeiros de projetos de segurança, com o envio de agentes policiais, como os da Força Nacional, e a criação de um Gabinete Integrado de Gestão Fronteiriça-GGIFRON (focado apenas na segurança e no controle da criminalidade). O papel das Forças Armadas também tem mudado ao receber atribuições policiais, realizando revistas e batidas em estradas e em estabelecimentos comerciais da cidade. A atuação das Forças Armadas em campanhas sanitárias e de saúde é anterior a esse processo de securitização ${ }^{4}$ das fronteiras brasileiras, mas também vem sendo ressemantizada, incorporando novos discursos, procurando legitimar-se em outros campos de atuação que não apenas aqueles da defesa armada do território, a reforçar a gramática da "militarização" das fronteiras. Assim, cada vez mais a fronteira é representada por discursos e planos estatais que a reduzem a uma dimensão moral quase única: como local perigoso e que deve ser alvo de medidas de segurança específicas, tanto como foco de criminalidade, principalmente em torno do contrabando, do tráfico de drogas e de armas, quanto como lugar de contágio com um "outro" enfermo, "pobre" ou mesmo portador de uma cultura "diferente".

Para tentar relacionar essas questões apresentaremos alguns arranjos e configurações que modificaram recentemente as relações de força na fronteira, impondo cada vez mais uma governamentalidade calcada na segurança nacional, de "proteção à nação", a partir da visão militar do Estado. Em primeiro lugar, destacamos a publicação do Decreto no 6.703 que aprovou a criação da "Estratégia Nacional de Defesa", em 2008 (www.defesa.org.br). Como possíveis efeitos da implantação dessas diretrizes de monitoramento e vigilância, deu-se a criação e implantação do Plano Estratégico de Fronteiras (PEF), em 2011, que tem como um de seus objetivos centrais "o fortalecimento da prevenção, controle, fiscalização e repressão dos delitos transfronteiriços e dos delitos praticados na faixa de fronteira brasileira" (Brasil, 2012). No mes- 
mo ano é instituída a Estratégia Nacional de Segurança nas Fronteiras (Enafron), cujo conceito é definido como um

Conjunto de políticas e projetos do Governo Federal que tem por finalidade melhorar a percepção de segurança pública junto à sociedade e garantir a presença permanente das instituições policiais e de fiscalização na região de fronteira do Brasil, otimizando a prevenção e a repressão aos crimes transfronteiriços, por meio de ações integradas de diversos órgãos federais, estaduais e municipais. (http://www2.camara. leg.br/)

Uma importante etapa da Enafron é a produção de pesquisas e diagnósticos sobre a situação da segurança nas fronteiras. As universidades dos estados fronteiriços foram chamadas nesse momento para realizar pesquisas, como no recente projeto da Secretaria Nacional de Segurança Pública (Senasp), sob o comando do Ministério da Justiça, a partir da coordenação conjunta de dois importantes Grupos de Pesquisa: o Núcleo de Estudos da Cidadania, Conflito e Violência Urbana da Universidade Federal do Rio de Janeiro (UFRJ) Núcleo de Estudos da Cidadania, Conflito e Violência Urbana (NECVU), e o Grupo Retis, também da UFRJ (Neves et al., 2016).

O PEF desencadeou uma série de ações para reforçar a vigilância e monitoramento das fronteiras brasileiras, e que tiveram grande impacto local em Corumbá, com o aumento do efetivo do aparato de segurança, com a presença ostensiva da Força Nacional na cidade, e, também, em operações nas quais as Forças Armadas passaram a executar cada vez mais o papel de polícia na fronteira. No mesmo ano foi criado o Gabinete de Gestão Integrada de Fronteira (Ggifron), da Secretaria de Estado de Justiça e Segurança Pública/MS, responsável pela gestão integrada das forças de segurança na fronteira para o combate aos "crimes fronteiriços".

Em 2013, por sua vez, foi implantado o Sistema de Monitoramento de Fronteiras (Sisfron), em Mato Grosso do Sul, que previa a instalação de dois centros de operações, além de um pelotão de comunicação e um da Polícia do Exército na cidade de Corumbá. De acordo com reportagem veiculada pelo Correio de Corumbá, em 25 de abril de 2014, criaram-se grandes expectativas políticas e econômicas na cidade em torno desse projeto vinculado às Forças Armadas (Exército Brasileiro):

O General Juarez destacou que o SISFRON vai reduzir o índice de criminalidade, o contrabando e o narcotráfico na fronteira de Mato Grosso 
do Sul. A Polícia Federal estima que o Estado responde por $80 \%$ da droga apreendida no Brasil. Além de combater a violência, de acordo com o comandante do CMO (Comando Militar do Oeste), o sistema de monitoramento irá gerar empregos e implementar o desenvolvimento econômico da região. O SISFRON irá exigir a contratação de funcionários e instalação de empresas para prestar serviços nas áreas de comunicação de dados, informática e manutenção. (www.correiodecorumba.com.br, 25 de abril de 2014)

De acordo com Dorfman (2013), estão implícitos nesses discursos e nessas diretrizes a criminalização das regiões de fronteira e sua reconfiguração como "lugares do crime". Essa autora afirma ainda que

a região de fronteira corre o risco de se transformar na ameaça à segurança pública, reforçando uma geografia moral em que diferentes lugares do espaço são representados como dotados de características morais e a fronteira estimula valores como impureza, ameaça e delinquência. A estigmatização desse objeto geográfico, pressupondo uma influência moral sobre seus habitantes, decorre da mudança legal e territorial e da situação periférica que leva ao contato / contágio com o estrangeiro. (Dorfman, 2013:16)

Observamos, portanto, a crescente interseção dos discursos de segurança nacional e de segurança pública nas regiões de fronteira, que redesenham as políticas e práticas nesses locais (Alvarez e Salla, 2013). As políticas para a fronteira que partem, em grande medida, do pressuposto de que essas são regiões a serem vigiadas ou regiões perigosas, acabam reificando-as como possíveis "lugares de exceção", em que todos são suspeitos em potencial, em que se exerce o "caráter extralegal da dimensão coercitiva dos controles sociais que organizam o sistema de dominação" (Machado da Silva, 2014:19) As batidas policiais nos ônibus, por exemplo, e as perguntas feitas pelos policiais federais ou pelo Departamento de Operações de Fronteira, da Polícia Militar DOF: "Mora em Corumbá? Vai pra onde? Trabalha onde? Vai fazer o quê em Campo Grande?", que, ao mesmo tempo em que procuram coibir os crimes fronteiriços, na busca por possíveis suspeitos, afetam a privacidade das pessoas em um ritual de passagem no qual, temporariamente, podem estar suspensos pressupostos legais como o direito de ir e vir. Essas perguntas funcionam como um rito de autoridade e informam que aquele não é um território de livre passagem, e que o controle e poder se materializam na figura discricionária do agente do Estado.

DADOS - Revista de Ciências Sociais, Rio de Janeiro, vol. 61, no 2, 2018 


\section{Gustavo Villela Lima da Costa}

Outro fator presente nesses procedimentos policiais corriqueiros nas áreas de fronteira é a distinção, realizada por Oliveira (2013), entre o policial $d a$ fronteira e o policial de fronteira. Em geral, os policiais $d a$ fronteira são indivíduos da região, nascidos ou criados nessas cidades de fronteira e que conhecem, a partir de suas vivências, as idiossincrasias da vida fronteiriça. Esses policiais estão imbricados em relações sociais a partir do conhecimento direto das pessoas ou parentesco, o que permite uma gestão personalizada dos conflitos e uma informação mais acurada "das ruas". Esses agentes, em geral, convivem com a suspeita de que podem estar envolvidos em redes criminosas ("corrupção"), ou que possam sofrer represálias de criminosos caso atuem com imparcialidade e rigor, dentro dos padrões ideais de conduta. Todos em Corumbá têm um nome, um rosto, um cargo, uma reputação. Além disso, as pessoas podem ser vizinhas, parentes, colegas de trabalho, mas, ao mesmo tempo, são vizinhas de alguém que é parente de um colega do trabalho, ou são casadas com parentes ou comadres de algum vizinho ou colega de trabalho, formando uma rede intrincada de circuitos sociais de fofoca na cidade.

Ao contrário, os policiais de fronteira (e outros agentes de segurança, como militares e agentes da Força Nacional) não são nascidos nessas regiões de fronteira, estão ali de passagem, e, em sua maioria, vêm de grandes centros urbanos, onde a violência e a impessoalidade são traços característicos dos seus procedimentos de trabalho, nos quais prevalece a "linguagem da violência urbana" sobre a "linguagem dos direitos" na manutenção da ordem pública (Machado da Silva, 2014). Os discursos que entendem a fronteira apenas como limite entre países, e como área de segurança nacional, são constituintes da formação desses agentes, que incorporam a defesa do território nacional como parte de sua "missão" durante sua permanência nas cidades fronteiriças.

Esses dispositivos de poder atuam sobre a circulação de pessoas e mercadorias na fronteira, "governamentalizando" e disciplinando não apenas os moradores dessas regiões - sobretudo aqueles que dependem da fronteira para sobreviver-, mas também os próprios funcionários do Estado e outros segmentos sociais. Esses são dispositivos voltados fundamentalmente para a segurança nacional e não se referem a outros elementos de uma possível "gestão integrada" da fronteira como a cultura, educação e geração de emprego e renda. É importante destacar que, no último censo do IBGE (IBGE, 2010), a cidade de Corumbá aparece com o índice de incidência de pobreza em $40 \%$, o que 
aponta para questões como a concentração de renda, a desigualdade social, o desemprego e a precarização do trabalho em uma região na qual circula muita riqueza que não se distribui, sobretudo, na geração de empregos. Entre as principais atividades econômicas da região estão a mineração no maciço do Urucum, explorada pela Vale (Ferro e Manganês), a criação de gado em fazendas no Pantanal, o turismo de pesca e comércio de exportação e importação. Além disso, a falta de empregos e oportunidades na cidade se reflete no baixo crescimento populacional, o que indica que a saída para parte da população é a migração para outras cidades, principalmente para a capital do estado, Campo Grande. Uma fala comum das pessoas é a de que "tem outra Corumbá em Campo Grande". Em 1991, de acordo com os dados dos censos do IBGE, havia em torno de 88 mil habitantes; em 2000, em torno de 95 mil habitantes; e em 2010, em torno de 103 mil pessoas. Assim, gerir a fronteira a partir do paradigma da segurança nacional é uma escolha política que despolitiza e silencia outras questões, e limita as possibilidades de implantação de políticas públicas binacionais e demandas sociais, educacionais e culturais na região.

O Estado, como afirmam Das e Poole (2008), não tende, portanto, a se desarticular ou a se debilitar em suas margens territoriais ou sociais muito pelo contrário. De acordo com as autoras, nessas margens se tornam mais visíveis os pressupostos necessários para o funcionamento do Estado que, aí continuamente, redefine seus modos de governar, legislar e de controlar tanto o território quanto as populações. Nesse sentido, interessa-nos pensar em como o Estado põe em prática mecanismos que podem garantir ou deslegitimar as identidades na fronteira, tendo como símbolo paradigmático o "posto de controle" como "espacio lleno de tensión en el que los supuestos acerca de la seguridad de la identidad y de los derechos pueden ser repentinamente y, a veces, violentamente negados" (Das e Poole, 2008:24).

Agamben (2002) contribui para o nosso debate ao defender a tese de que o estado de exceção é uma estrutura fundamental do Estado moderno, e que tende a tornar-se regra, a se estabilizar como mecanismo de poder. Para esse autor, o estado de exceção entendido no senso comum como uma suspensão temporal da norma, do ordenamento, torna-se cada vez mais uma nova e estável disposição espacial de poder. Entendemos que o caráter ambíguo e liminar da fronteira, de difícil regulação por parte dos Estados nacionais, contribui para torná-la um espaço tutelado onde o ordenamento legal, e mesmo os acordos tácitos 
e informais, podem ser suspensos a qualquer momento, sobretudo em momentos de conflito. Ferreira (2009) entende que a fronteira pode ser analisada como um "laboratório de políticas de controle" e, como observamos aqui, a fronteira como "margem" abre espaço para um conjunto de práticas de exceção, em função das políticas de securitização legitimadas por discursos de segurança nacional. Isso nos permite pensá-la como um lugar-paradigma do exercício do poder soberano do Estado, a partir do qual exerce suas práticas baseadas tanto em um modelo jurídico e territorial quanto em um modelo biopolítico de poder. Assim, a fronteira como espaço tutelado e "perigoso", como um portal acessível ao "outro", torna-se um local onde o poder sempre pode se colocar tanto dentro como acima da lei, sob as mais diversas alegações como tráfico de drogas, migração "ilegal", contrabando e descaminho, questões sanitárias - e assim por diante.

No caso de Corumbá, a fronteira como um possível lugar de exceção é simbolizada não apenas nas revistas de rotina, mas principalmente pelo significativo contingente militar que passou a atuar em operações "civis", executando o papel de polícia, em muitas ocasiões, a partir do recente processo de securitização das fronteiras brasileiras. Dois exemplos recentes, ocorridos em 2013, foram o fechamento da Feira Bras-Bol e o fechamento das "lojinhas", nas quais trabalhavam majoritariamente bolivianos, ou brasileiros de origem boliviana. $\mathrm{O}$ fechamento das "lojinhas", dos pequenos comércios estabelecidos em imóveis de Corumbá, ocorreu numa operação denominada "No Caminho", com a presença ostensiva da Polícia Federal e de agentes da Receita Federal, e contou com o apoio do exército, com caminhões, soldados e armamento pesado circulando pela cidade, com um efetivo desproporcional e inédito para apreender mercadorias de comerciantes. Embora parte das mercadorias estivesse fora dos padrões legais e não tivesse nota fiscal, houve repercussão nas mídias sociais (tanto no Brasil, quanto na Bolívia) sobre agressões sofridas por mulheres comerciantes bolivianas, além da apreensão de mercadorias legais, com nota fiscal, durante a operação. Essa não foi uma operação que visou apenas apreender mercadorias ilegais, mas que teve a intenção de fechar os pontos de comércio cujos donos são de origem boliviana (apreendendo todas as mercadorias, mesmo as legais), indicando, simbolicamente, que aquele território e a cidade não tolerariam mais o comércio "ilegal" e exercido por "estrangeiros". Essas operações de segurança têm, ainda, um caráter de teatralidade, de espetacularização da presença estatal na fronteira, afirmando o poder simbólico do Esta- 
do, na figura do exército, essencial para a manutenção do seu poder efetivo.

\section{BIOPOLÍTICA NA FRONTEIRA: IDENTIDADE, NAÇÃO E SAÚDE PÚBLICA}

A atuação das Forças Armadas e o processo de securitização da saúde pública como um problema de saúde "nacional" são bem anteriores às novas políticas de segurança e à reconfiguração da atuação das Forças Armadas como forças policiais na região. Entretanto, essa atuação tanto de atendimento e suporte ao atendimento de saúde para regiões isoladas, ou mesmo de instalação de barreiras à entrada de enfermidades na fronteira "vindas" de outros países, foram incorporadas aos discursos de legitimação da presença militar, reforçando sua importância e atuação nas regiões de fronteira. Como também há grande visibilidade dessas operações sanitárias e de saúde pública, nota-se a referida dimensão simbólica e de espetacularização da presença militar e de autoridades, o que contribui para sua eficácia e legitimidade ao demonstrar que as forças armadas não atuam apenas na repressão e controle (atualizando nesses rituais de atuação, nessas operações como "performances", o lema do Exército Brasileiro: "Braço forte, mão amiga").

A articulação entre as políticas de segurança e de saúde pública na fronteira, em Corumbá, pode ser percebida, por exemplo, na principal operação de controle e vigilância das fronteiras brasileiras: a operação Ágata, que ocorreu pela décima primeira vez em 2016, dessa vez com a presença do Ministro da Defesa, Raul Jungmann, que esteve em Corumbá e Ladário no dia 18 de junho daquele ano. Durante a navegação pelo Rio Paraguai, o Ministro da Defesa acompanhou os atendimentos médicos e odontológicos à população ribeirinha do Pantanal, realizados pelo Navio de Assistência Hospitalar "Tenente Maximiano", da Marinha, e pela embarcação "Forte Coimbra", do Exército Brasileiro.

Em entrevista publicada no portal da Marinha do Brasil, o Ministro Raul Jungmann afirmou, então, que a presença do Estado brasileiro em uma região de fronteira exige que as "instituições trabalhem de forma integrada". Essa integração, como se percebe pela atuação dos órgãos participantes, envolve principalmente instituições estatais ligadas à segurança e saúde (vigilância sanitária) e às questões ambientais. As ações de saúde pública visam não apenas criar barreiras para enfermidades na fronteira, mas também atender as populações ribeirinhas e indígenas ao longo do rio Paraguai. A Operação Ágata (deflagrada em

DADOS - Revista de Ciências Sociais, Rio de Janeiro, vol. 61, n’ 2, 2018 
vários pontos da fronteira brasileira, contou com 18 mil militares da Marinha, do Exército e da Aeronáutica). Além desse total, participaram agentes da Polícia Federal, Polícia Rodoviária Federal, Receita Federal, Instituto Brasileiro do Meio Ambiente, Fundação Nacional do Índio, Agência Nacional de Aviação Civil, Agência Brasileira de Inteligência, Agência Nacional de Vigilância Sanitária, Ministério da Agricultura, Pecuária e Abastecimento, Ministério Público Federal, Ministério Público Militar, entre outros. Todo esse aparato corrobora a ideia de Das e Poole (2008) de que o Estado está bastante presente nas suas "margens", atuando de forma específica nessas regiões.

Nos últimos anos ocorreram, portanto, uma série de ações conjuntas entre órgãos de saúde pública e de segurança nacional atuando de modo conjunto na fronteira. No dia 17 de julho de 2009, por exemplo, o Ministério da Defesa atuou em 24 cidades de fronteira, espalhadas por dez estados do Brasil. Os militares foram incumbidos da tarefa de divulgar informações sobre a prevenção da gripe suína. A solicitação de apoio foi feita pela Agência Nacional de Vigilância Sanitária (Anvisa), que pediu a mobilização de 78 militares no total. A nota do ministério da Defesa afirma que "a preocupação maior é dar o esclarecimento adequado aos viajantes que cruzam, principalmente, as fronteiras do Brasil com Argentina, Uruguai e Paraguai, mas também estão sendo realizados esforços no Norte e Centro-Oeste do país" (https://noticias.uol.com.br).

No dia 31 de agosto de 2010, por sua vez, a Prefeitura de Corumbá lançou o projeto Fronteira Bras-Bol - parcerias no combate a endemias na fronteira entre o Brasil e a Bolívia. Essas foram ações voltadas à prevenção e combate a doenças, principalmente dengue, raiva e leishmaniose. A ação fez parte de uma estratégia adotada pela Prefeitura por meio da Secretaria Executiva de Saúde Pública, com apoio da Secretaria Executiva de Meio Ambiente. Participaram da ação a Agência Nacional de Vigilância Sanitária, o Exército Brasileiro, a Receita Federal, a Polícia Federal; o Consulado da Bolívia, as Forças Armadas da Bolívia e técnicos em saúde e diretores da província de German Busch.

Há também uma série de ações voltadas para a saúde pública em Corumbá que contam com a participação das Forças Armadas e que não estão relacionadas diretamente à fronteira e às relações com as cidades bolivianas vizinhas. Entre os exemplos, destacamos o que foi considerado pelos jornais locais como uma "verdadeira operação de guerra" 
montada pelo Governo Federal em parceria com os governos estaduais, prefeituras, e as Forças Armadas para realizarem, em 13 de agosto de 2016, o Dia Nacional de Mobilização para o Combate ao Aedes aegypti. Cerca de 350 municípios de todo o país receberam esta força tarefa, e, em Corumbá, o Exército Brasileiro, através de militares do 17은 Batalhão de Fronteira, em conjunto com agentes municipais de endemias, mobilizaram-se para sair à campo, com o objetivo de visitar as 37 mil residências da área urbana na cidade (http://www.corumba.ms.gov.br). Essas ações reforçam cotidianamente o que chamamos de ethos militar em Corumbá, em que o campo e visibilidade das ações militares na cidade são bem peculiares e bastante visíveis.

A relação entre o nascimento e morte, saúde e doença (biologia) e a cidadania e nacionalidade (política) se insere na crescente implicação da vida natural dos seres humanos nos mecanismos, cálculos, técnicas e procedimentos do poder, no que Foucault (2010) denomina como biopolítica, cujas tecnologias de poder são dirigidas à massa da população, à multiplicidade de indivíduos (e não apenas aos corpos individuais). É aí que a Medicina Social - como um saber-poder que tanto tem efeitos disciplinares quanto regulamentadores - exerce sua função de promover a higiene pública, de coordenar os tratamentos, vacinações e campanhas públicas, cujos efeitos são a "normalização" da população a partir de sua higienização e medicalização. Na fronteira, esses dispositivos de poder contribuem para a reprodução das diferenças entre a população do lado brasileiro e a do lado boliviano. A fronteira é entendida por órgãos públicos, por agentes de saúde, e mesmo pela população de Corumbá, como um desafio a essa "normalização" e ao controle de enfermidades. Quem, portanto, está fora dos padrões e das normas na fronteira? A quem esses mecanismos reguladores do Estado se dirigem com mais ênfase?

As doenças são vistas como uma ameaça constante que vem do lado boliviano, a demandar a atuação de organismos de cooperação binacionais e a criação de campanhas bilíngues na fronteira de "aprendizado de higiene e medicalização da população". (Foucault 2010:205) O controle de zoonoses como a febre aftosa, e de doenças como dengue, raiva, e leishmaniose, em geral, são feitos em parceria (com a predominância de ações e investimentos do lado brasileiro), o que reforça a imagem da fronteira como área de contágio. É preciso destacar que a área de saúde é uma das mais integradas do ponto de vista da cooperação binacional e há importantes esforços conjuntos de controle de en- 


\section{Gustavo Villela Lima da Costa}

fermidades por parte das prefeituras das cidades fronteiriças. Não se questiona a efetividade dessas políticas públicas, e muito menos a necessidade de execução dos controles sanitários e médicos. O que se discute, aqui, é o fato de que há uma maior participação brasileira no lado boliviano do que o contrário. Raramente, os agentes de saúde bolivianos são chamados a atuar no lado brasileiro, e, tampouco, há a possibilidade de controle fora dos limites do Estado boliviano por parte desses mesmos agentes, ainda que haja epidemias ou problemas de saúde cujos vetores estejam no lado brasileiro e sejam uma ameaça à saúde para a Bolívia e sua população. São essas assimetrias que nos chamam a atenção e merecem a nossa reflexão.

Está presente aí a ideia de que o Brasil está em uma posição de "superioridade" e que "deve ajudar" a Bolívia a controlar essas enfermidades de forma "benevolente" e "pedagógica", tutelando a fronteira, as cidades bolivianas vizinhas e sua população. Além disso, a fronteira é vista como a ameaça real que possibilita o contágio da população "brasileira": são doenças que vêm do "outro lado". As próprias Prefeituras de Puerto Quijarro e Puerto Suarez solicitam, em alguns momentos, a ajuda da Prefeitura de Corumbá, alegando falta de recursos para o combate às enfermidades, reproduzindo essa posição de inferioridade, muitas vezes, de modo estratégico, a fim de conseguir recursos e profissionais de saúde brasileiros para atuarem nesses municípios. Observa-se essa questão em algumas notícias referentes ao combate à dengue e à raiva na fronteira: a primeira, de 2010, retirada da página da Prefeitura de Corumbá, e as outras duas notícias de dois jornais locais - uma, de 2012, e outra, de 2015 (grifos meus).

Duas cidades bolivianas deverão receber ajuda de Corumbá, a partir dessa semana, com ações de combate à dengue. Na terça-feira, equipes da Secretaria Executiva de Saúde Pública da Prefeitura Municipal estarão reunidas com autoridades bolivianas das cidades de Puerto Quijarro e Puerto Suarez, definindo estratégia a ser adotada nas duas cidades bolivianas que fazem fronteira com o Brasil, nesta região. A solicitação foi feita na última sexta-feira. Os bolivianos residentes nas duas cidades estão temerosos diante do quadro de epidemia da dengue em Santa Cruz de La Sierra. "Estamos apenas aguardando o envio de inseticida por parte do Governo do Estado, para iniciarmos o trabalho na Bolívia", explicou, lembrando que $a$ ação em território boliviano é importante para conter o avanço da doença nesta região de fronteira. (www.corumba.ms.gov.br, 5/07/2010)

Antes mesmo de sair o resultado do levantamento, a subsecretária de Saúde [...] demonstra enorme preocupação com a situação do outro lado da 
fronteira. No sábado, em Quijarro, ela conversou bastante com a coordenadora geral de Vigilância em Saúde da Prefeitura de Corumbá, [...], já tratando de estratégias que devem ser adotadas para conter avanço da doença. Observou que Corumbá, por uma orientação do prefeito Ruiter Cunha, dará total apoio às autoridades bolivianas no desenvolvimento de uma campanha contra a dengue. [...] Como se sabe, algumas regiões da Bolívia estão com epidemias de dengue, e as ações desencadeadas nas cidades fronteiriças com Corumbá são justamente para evitar que a doença avance na região. Em Puerto Suarez já está decidida a realização de um grande mutirão de limpeza para eliminação dos focos. O mesmo deve ser seguido em Quijarro e Concepción. Estas estratégias terão apoio também da Prefeitura de Corumbá. (www.perolanews.com.br, 27/2/2012)

Os 15 casos de raiva de animal confirmados em Corumbá (14 laboratorialmente e 1 por dedução) apresentaram o que os especialistas chamam de "variante 1 " da doença. É o tipo mais comumente achado no território boliviano. Por isso, uma parceria da Prefeitura de Corumbá, por meio da Secretaria Municipal de Saúde, da Secretaria de Saúde de Campo Grande, da Secretaria Estadual de Saúde e da Organização Pan-Americana da Saúde (OPAS), vai viabilizar a imunização, a partir da primeira semana de maio, dos animais de Puerto Quijarro e Puerto Suárez, na fronteira com o Brasil. (www.correiodecorumba.com.br, 27/4/2015)

Além das atuações em campanhas sanitárias na fronteira, há a questão do atendimento médico de bolivianos nos hospitais e maternidades no lado brasileiro. O Sistema Único de Saúde brasileiro (SUS) ${ }^{5}$ garante o atendimento médico de todo estrangeiro que estiver no Brasil, mesmo que em viagem, e em casos de emergência. Há, porém, limites para os tratamentos a estrangeiros, pois esse benefício não é estendido aos estrangeiros que pretendem usar o SUS em tratamentos eletivos e que não residem no país. Ainda assim, de acordo com a direção da Santa Casa de Corumbá, alguns bolivianos que não moram no Brasil "estão dando entrada" em tratamentos no setor de oncologia e hemodiálise, por exemplo. Há, portanto, nessa legislação, um princípio universalista, que rompe, na fronteira, com a lógica binária de identificação entre "nós" e "eles", entre o "nacional" e o "estrangeiro". Esse princípio legal para o atendimento médico, sobretudo em casos de emergência, impõe alguma indistinção social ao paciente, visto como um ser humano que precisa de tratamento (e não como "brasileiro", ou "boliviano"). Há, então, um certo grau de impessoalidade que coloca, por sua vez, alguns limites à atuação livre do princípio discricionário dos agentes de saúde (médicos e enfermeiros) que precisam atender os pa- 


\section{Gustavo Villela Lima da Costa}

cientes. Albuquerque (2012) aponta, no caso da fronteira Brasil-Paraguai, para os conflitos subjetivos e dilemas morais vivenciados no cotidiano pelos profissionais de saúde entre o nacionalismo, os direitos humanos, entre registrar ou não registrar, atender ou não atender. Esse exemplo demonstra o que Elias (1997) chama de dualidade dos códigos normativos dos Estados nacionais que, na verdade, é um duplo código, em grande medida, de normas contraditórias e incompatíveis, e que vão formar os habitus nacionais: de um lado, um código igualitário, centrado no indivíduo (valores como igualdade, direitos humanos e legislações como a do atendimento universal do SUS); e, de outro, um código hierárquico, etnocêntrico, cujo valor maior é a coletividade à qual pertence o indivíduo (no caso, a nação como a crença secular moderna). Está presente aí a ideia de que a igualdade é reservada aos "iguais", enquanto a diferença se dirige aos "diferentes". Para Elias (idem), ainda esses códigos de normas tendem a unir as pessoas umas às outras (internamente), e que, depois de unidas, colocam-se umas contra as outras (externamente), formando tanto princípios de coesão quanto de conflito, como vemos com maior destaque nas cidades de fronteira:

Dessa forma, as políticas e as ações em nome da saúde pública, nessa região de múltiplas fronteiras, traduzem tensões e dilemas relacionados às reivindicações de alguns monopólios do Estado soberano moderno, tais como os monopólios dos tributos e da cidadania nacional. Mas também aponta para um complexo movimento de ampliação de direitos sociais em uma zona de alguns projetos e práticas de integração fronteiriça. Os direitos universais, a vida e a saúde entram em colisão com os limites orçamentários dos setores de saúde e a defesa do atendimento somente para os residentes daquele município ou de outra cidade brasileira. (Albuquerque, 2012:203)

Mesmo com as garantias legais de atendimento universal, a atuação personalizada de agentes de saúde não está ausente nas escolhas e procedimentos médicos nas unidades de saúde na fronteira. Entretanto, nos casos de emergência, como é o caso de gestantes em trabalho de parto, significa que, mesmo contra a vontade de alguns, o paciente estrangeiro deverá ser atendido na rede pública. No artigo de Olivar, Cunha e Rosa (2015), os autores abordam essa capilaridade dos dispositivos de desigualdade, na atuação de agentes de saúde, em Tabatinga, na Amazônia, quando descrevem que uma enfermeira local, seguindo orientações do seu "chefe"", não entrega a carteira de gestante 
a uma mãe peruana, por desconfiar se a mesma possui, de fato, a dupla nacionalidade. Citando a pesquisa de Campos (2012) demonstram narrativas de desprezo dos agentes de saúde, no lado brasileiro, com pré-julgamentos morais sobre a suposta "malandragem" das gestantes peruanas, e que essa resistência em as atender chega ao extremo de colocar em risco a vida da mãe e do bebê (ibidem:144). Essa situação em que duas lógicas, uma universal (e legal), que garante o atendimento de todos, e outra, exclusivista (podendo estar na esfera pessoal dos médicos, por exemplo), que pressupõe que os serviços de um determinado país seriam disponibilizados apenas aos nacionais, acaba sendo um foco de grande tensão na fronteira, como apontam Branco e Torronteguy (2013).

Isso ocorre, em grande medida, de acordo com esses autores (ibidem), porque no Brasil não há um marco regulatório único que trate do direito do estrangeiro ao sistema de saúde brasileiro - com exceção de acordos estabelecidos com o país vizinho, conforme interesses brasileiros e dependendo da relação política existente -, nem normas e regras aplicáveis a todas as cidades de fronteira no que diz respeito à saúde. Por essa razão, esses pesquisadores apontam que a decisão acaba sendo do gestor local, que passa a exercer um poder discricionário, pois não há jurisprudência quanto ao direito do estrangeiro fronteiriço ao Sistema Único de Saúde, bem como aporte de recurso estadual ou federal para que o município fronteiriço atenda a essa demanda. Assim, a gestão pessoal tem grande importância na saúde pública, em que acordos tácitos entre prefeituras de cidades dos países, ou mesmo construídos na prática cotidiana, determinam até onde se deve atender o estrangeiro (com limites nos casos de emergências, entre os quais, a realização dos partos).

Albuquerque aponta as tensões entre uma territorialização fixa, dada tanto pela política ou pelo direito nacionais, e as dinâmicas em movimento da vida fronteiriça, entendidas, estas, como espaços liminares de "difícil exercício do monopólio da violência, da lei, dos tributos, da cultura nacional e dos documentos de identidade" (Albuquerque, 2012:188). Sua pesquisa sobre a utilização do SUS por parte de paraguaios e brasiguaios na fronteira, entre Foz do Iguaçu e Ciudad del Este, aponta para essas tensões e estratégias dos moradores na busca por direitos sociais, em meio a um dogma nacional e estatal de que os mesmos dependem de quem paga os tributos (seja em nível municipal, estadual ou federal), cujos efeitos sociais são, em geral, a deslegitima- 


\section{Gustavo Villela Lima da Costa}

ção dessas demandas por atendimento no sistema de saúde, no lado brasileiro. Nesse contexto, emerge a noção de Albuquerque da existência de uma "cidadania liminar", que serve para analisarmos nosso caso em questão e pensarmos "a dimensão transitória e contraditória do exercício de uma cidadania social que se constrói de maneira marginal entre territórios nacionais em um contexto de integração regional" (ibidem:191).

A partir dessas "brechas" no sistema, algumas estratégias de sobrevivência para conseguir atendimento médico no lado brasileiro são utilizadas por bolivianos residentes em Puerto Quijarro e Puerto Suarez, como obter o cartão do SUS e CPF mesmo sem o RG (carteira de identidade brasileira), nem a Cédula de Identificação de Estrangeiro, emitida pela Polícia Federal, e exigida para confecção do cartão SUS em Corumbá. Em geral, essas pessoas apresentam sua carteira de identidade boliviana e informam um endereço no lado brasileiro como se residissem em Corumbá, o que permite a retirada de alguns desses documentos (estratégias similares foram identificadas por Albuquerque (2015), na fronteira Brasil-Paraguai):

Embora a Constituição Federal diga expressamente, em seu Art.196, que a saúde é um direito de todos e dever do Estado, nem todos os gestores públicos e operadores do direito têm esse mesmo entendimento, muitos divergem na interpretação da Lei. A questão é quem são esses "todos" que a Constituição quer dizer, todos os cidadãos brasileiros ou todas as pessoas que procuram o sistema de saúde? Todos os brasileiros natos e naturalizados ou também o estrangeiro? E o estrangeiro fronteiriço deve ser tratado de forma diferenciada pela sua condição de fronteiriço? E em que medida deverá ser assegurado o atendimento desse estrangeiro fronteiriço: urgência e emergência, ou também consultas eletivas? Essa diversidade de interpretação tem gerado grandes conflitos, e nem sempre esses conflitos são registrados, uma vez que o estrangeiro fronteiriço que tem seu atendimento negado não tem meios de acionar a justiça brasileira, além de gerar grandes dificuldades ao município cujo gestor de saúde decide autorizar o atendimento do estrangeiro no sistema de saúde, pois nem o Estado nem a União reconhecem esse atendimento, não repassando recursos correspondentes a essa demanda nem ressarcimento a esses atendimentos. (Branco e Torronteguy, 2013:937)

Um exemplo paradigmático desses conflitos em Corumbá é o caso das gestantes bolivianas que buscam atendimento na maternidade muni- 
cipal. Aí necessariamente se coloca, de forma direta, a relação entre poder soberano e o direito à vida, e a importância da biopolítica e da saúde como atribuições do Estado, que deve se preocupar com a "vida", organizá-la, multiplicá-la a partir de mecanismos reguladores da população (mesmo que estrangeira). Uma importante questão relativa à cidade de Corumbá tem a ver com as demandas por estudos para mapear os nascimentos de crianças de mães bolivianas, para incorporá-las às estatísticas da população total atendida, a fim de reivindicar mais verbas para a Prefeitura Municipal de Corumbá, em função da sobrecarga do sistema, principalmente pelo atendimento de estrangeiros e cidades vizinhas.

Há também um debate constante na cidade a respeito dos direitos das gestantes e dos bebês, da legitimidade do atendimento de mulheres de outro país sob a precariedade do sistema de saúde no lado brasileiro. Nestes discursos aparecem tanto os preconceitos, o racismo, quanto diferentes concepções sobre obrigações, direitos e deveres, assim como posicionamentos sobre solidariedade e direitos humanos: deve-se atender as gestantes bolivianas na maternidade municipal ou não? É obrigação da prefeitura? Do Estado brasileiro? Do Estado boliviano? Uma fala comum em conversas na cidade: - "Mas se mal temos atendimento decente em Corumbá, porque devemos atender estrangeiros? Quem paga a conta?", ou, então, - "Os bolivianos só querem escola, hospital aqui no Brasil... não querem pagar por nada". Nesse debate circulam, dos dois lados da fronteira, diferentes concepções sobre direitos e deveres dos moradores fronteiriços, além do fato de que há a obrigatoriedade legal de atender os pacientes, mesmo que não estejam cadastrados noSUS, por serem estrangeiros. Essa estratégia fronteiriça envolve uma série de riscos para as mulheres, que esperam iniciar o trabalho de parto no lado boliviano para se dirigirem à maternidade de Corumbá. De acordo com o diretor-presidente da Santa Casa, "as mulheres dão entrada na maternidade de forma emergencial, no momento em que está ocorrendo o trabalho de parto, não podendo ser negado o socorro. Elas chegam já com contrações uterinas ou perda de líquido, já para ter a criança, então a gente tem que atender" (www.diarionline.com.br, 27/2/2016). O nascimento de crianças de origem boliviana nas maternidades do lado brasileiro pode ser entendido como um símbolo da condição liminar fronteiriça, na qual a própria identidade, associada ao corpo "biológico e político" desses atores sociais, ao longo do tempo, transitará nesse espaço intersticial. Cruzar a fronteira, em uma situação física-limite, com o trabalho de parto iniciado, é um

DADOS - Revista de Ciências Sociais, Rio de Janeiro, vol. 61, n’ 2, 2018 
ritual de passagem que altera o status social da criança recém-nascida, que terá a cidadania brasileira, apesar dos riscos de morte para os bebês e para as gestantes bolivianas. O nascimento em solo brasileiro (jus solis) produz a "mágica" de transformar o "outro" em "nós" em termos legais, e a aquisição desse direito é vista como ilegítima por parte de algumas pessoas do lado brasileiro, como uma cidadania que estivesse sempre em estado de suspeição em torno da lealdade nacional.

O que está em jogo para parte da população fronteiriça, principalmente os bolivianos que vivem em Puerto Quijarro e Puerto Suarez, é a ampliação de suas possibilidades de vida, de obter acesso a direitos nesse intenso fluxo binacional entre as cidades de Corumbá e Puerto Quijarro e Puerto Suarez. Assim, pode emergir uma visão absolutamente pragmática em relação à nacionalidade, como mais um recurso social e econômico para as crianças que nascem na maternidade de Corumbá. Essa possibilidade de escolha na fronteira impõe uma série de desafios ao poder público, produzindo discursos sobre nacionalidade e soberania; utilização e reivindicação de recursos federais, municipais e críticas à estrutura precária da casa de saúde de Corumbá; evocação de direitos humanos, de um lado, e restrição aos migrantes, xenofobia e racismo, de outro; solidariedade e integração, e também desconfiança e suspeita; discursos médicos e humanistas em defesa dos direitos da mulher gestante em meio a críticas ao excesso de pacientes estrangeiros, vindos do outro lado - além da ideia de que os bolivianos estariam burlando regras e disputando recursos e direitos sociais com os brasileiros.

\section{CONSIDERAÇÕES FINAIS}

Este artigo buscou compreender as relações entre a segurança nacional e a saúde pública como dispositivos estruturais da governamentalidade fronteiriça, que são forjados por uma mesma "gramática" nacionalista que reproduz a ideia de fronteira como limite demarcado entre "nós" e "eles", engendrando processos de sujeição, dominação e construção de sujeitos sociais. Procuramos pensar como o exercício do biopoder e do poder soberano produzem os grupos sociais na fronteira a partir de distintos dispositivos e técnicas de coerção e dominação, contribuindo para a reprodução da alteridade e das hierarquias sociais. A construção social desses indivíduos fronteiriços ocorre em meio a processos complexos de fronteirização, de pertencimento ao lugar e de (re)construções identitárias nas cidades de fronteira, entendidas não apenas 
como um recurso econômico para seus moradores, mas, também, como um recurso social, ou seja, como um "recurso simbólico" (Valcuende e Cardia, 2009).

Um segundo objetivo deste artigo foi demonstrar a predominância cada vez maior de discursos e práticas de um Estado "militar" sobre um Estado "social" e suas implicações no cotidiano das pessoas. Entre esses dispositivos de securitização postos em prática pelo Estado, destacamos a reconfiguração das políticas nacionais de segurança cujos efeitos sociais procuramos interpretar. Dessa forma, buscou-se entender como uma lógica militar instaurada como uma nova governamentalidade fronteiriça acaba influenciando outras práticas e políticas na fronteira, como é o caso da saúde pública, que entende a presença de um "outro" enfermo cada vez mais como uma ameaça à nação. A fronteira entendida de modo binário pelo Estado-nação como uma barreira na qual o "outro" está (e deve, preferencialmente, ficar) do "outro lado", serve como substrato comum a uma série de políticas públicas, e enseja discursos e representações nacionais e nacionalistas bastante exclusivistas, e que, em momentos de crise ou dependendo da conjuntura, adquirem matiz claramente xenófobo. A cidade de fronteira é representada como uma área que deve ser protegida do crime, das enfermidades alheias, e, mesmo em alguns momentos, da miscigenação cultural e linguística.

A fronteira é, portanto, um locus privilegiado para pensarmos que o Estado-nação e seus dispositivos, para além de suas normas jurídicas, continuam a ter um papel central nas relações de poder e podem apontar para situações similares em outros cenários de pesquisa. Esta investigação busca explicitar as formas de dominação, exclusão e o exercício da violência (física e simbólica) a partir de um conjunto de instituições estatais e atores sociais diversos em suas práticas, discursos, saberes e técnicas.

O que caracteriza também a vida na fronteira é a constante possibilidade de subversão e manipulação dos efeitos de poder desses dispositivos - que são tanto discursivos quanto não discursivos, e ao mesmo tempo jurídicos, técnicos, médicos, científicos e militares - por parte de determinados atores sociais. Observamos aqui essas práticas e estratégias de sobrevivência física e social no cruzamento das fronteiras-limites, principalmente na questão do atendimento das gestantes bolivianas no lado brasileiro. Em grande medida, esses dispositivos de 


\section{Gustavo Villela Lima da Costa}

poder, como redes tecidas ao longo do tempo entre instituições e sujeitos, entre o simbólico e o material, entre os discursos e práticas, estabelecem as regras do jogo de poder na fronteira (regras que existem também para serem transgredidas e modificadas). É em meio a esse campo desigual de disputas de poder que os atores sociais fronteiriços - principalmente, os bolivianos e seus descendentes em Corumbá - constroem suas trajetórias e produzem novos territórios e identidades enquanto agentes de suas próprias vidas, indo além dos paradigmas dos Estados-nação e da ubiquidade dos valores nacionais que tendem não apenas a recusar a alteridade na fronteira, mas, também, a (re)produzi-la de modo negativo, naturalizando e essencializando as diferenças.

Submetido em 20 de outubro de 2015

Reapresentado em 20 de abril de 2017

Reapresentado (2⿳亠丷⿵冂丶 vez) em 22 de fevereiro de 2018

Aprovado em 30 de julho de 2018 


\section{NOTAS}

1. Entre 2009 e 2013, atuei como docente da Universidade Federal de Mato Grosso do Sul (UFMS), no Campus do Pantanal, e no Mestrado em Estudos Fronteiriços. Alguns dados recolhidos entre 2014 e 2016 também são utilizados neste texto, porém, as pesquisas etnográficas foram realizadas nesses anos anteriores.

2. O conceito de governamentalidade é definido por Foucault como "o conjunto constituído pelas instituições, procedimentos, análises e reflexões, cálculos e táticas que permitem exercer esta forma bastante específica e complexa de poder, que tem por alvo a população, por forma principal de saber a Economia Política, e por instrumentos técnicos essenciais, os dispositivos de segurança" (Foucault, 1979:293)

3. Dispositivo: "um conjunto decididamente heterogêneo que engloba discursos, instituições, organizações arquitetônicas, decisões regulamentares, leis, medidas administrativas, enunciados científicos, proposições filosóficas, morais, filantrópicas. Em suma, o dito e o não dito são os elementos do dispositivo. O dispositivo é a rede que se pode tecer entre estes elementos" (Foucault, 2008:244).

4. Entende-se, nesse artigo, que a "securitização" pode ser entendida como um processo de natureza política, a partir do qual o Estado (e seus atores) trazem para o campo da segurança, distintos assuntos, como é o caso da saúde pública, comércio, imigração, entre outros (Buzan, Waever e De Wilde, 1998) Além disso, essa politização das questões de segurança permite a utilização de "meios extraordinários" para sua execução, o que envolve grande quantidade de recursos materiais e simbólicos para sua efetivação. Nesse sentido, procuramos observar como questões relativas ao trabalho, à saúde pública e à circulação de pessoas e mercadorias acabam sendo cada vez mais "securitizadas" na fronteira em um processo ainda em curso.

5. O Sistema Único de Saúde (SUS), que foi instaurado pela Constituição Federal de 1988, é gerido pelos municípios a partir de recursos próprios e do repasse de recursos das outras esferas de governo. O repasse é feito a partir do número de habitantes de cada município e de acordo com os dados oficiais do censo do Instituto Brasileiro de Geografia e Estatística - IBGE. Diante das reivindicações de políticas específicas das cidades de fronteira, o governo federal do Brasil criou o Sistema Integrado de Saúde das Fronteiras (SIS Fronteiras) em 2005, visando justamente ampliar os recursos para 121 municípios localizados em toda uma longa faixa de fronteiras (15.719 km) com nove países e com o departamento ultramarino da França (Guiana Francesa). O objetivo do programa é "promover a integração de ações e serviços de saúde na região de fronteira, contribuir para a organização e o fortalecimento dos sistemas locais de saúde nos municípios fronteiriços brasileiros" (Brasil, Ministério da Saúde, 2008:5).

DADOS - Revista de Ciências Sociais, Rio de Janeiro, vol. 61, n² 2, 2018 


\section{Gustavo Villela Lima da Costa}

\section{REFERÊNCIAS BIBLIOGRÁFICAS}

AGAMBEN, Giorgio. (2002), Homo Sacer: O Poder Soberano e a Vida Nua. Belo Horizonte, Editora UFMG.

ALBUQUERQUE, José Lindomar C. (2012), “Limites e Paradoxos da Cidadania no Território Fronteiriço: O Atendimento dos Brasiguaios no Sistema Público de Saúde em Foz do Iguaçu (Brasil)". Geopolítica(s), Madrid, vol. 3, no 2, pp. 185-205.

ALVAREZ, Marcos. César.; SALLA, Fernando. (2013), “Estado-nação, Fronteiras, Margens: Redesenhando os Espaços Fronteiriços no Brasil Contemporâneo". Civitas. Revista de Ciências Sociais, vol. 13, pp. 9-26.

BRANCO, Marisa Lucena; TORRONTEGUY, Marco Aurélio. (2013), “O SUS na Fronteira e o Direito: Em que Medida o Estrangeiro tem Direito ao SUS". Cadernos Ibero-Americanos de Direito Sanitário, vol. 2, no 2, jul./dez., pp. 932-945.

BRIONES, Claudia.; DEL CAIRO, Carlos. (2015), “Prácticas de Fronterización, Pluralización y Diferencia". Universitas Humanística, vol. 80, no 80, pp. 13-52.

BRASIL. (2012), Ministério da Justiça. Plano do Programa Enafron.

BOURDIEU, Pierre. (1989), O Poder Simbólico. Rio de Janeiro, Bertrand Brasil.

BUZAN, Barry; WAEVER, Ole; DE WILDE, Jaap. (1998), Security: A New Framework for Analysis. Boulder, Lynne Rienner Publishers.

COSTA, Gustavo V. L. (2013a), “O Muro Invisível: A Nacionalidade como Discurso Reificado na Fronteira Brasil-Bolívia”. Tempo Social, vol. 25, pp. 141-156.

. (2013b), “A Feira Bras-Bol, em Corumbá-MS: Notas sobre o Comércio Informal na Fronteira Brasil-Bolívia". Contemporânea. Revista de Sociologia da UFSCar, no 3, pp. 467-489.

. (2014a), “Conflitos e Disputas na Fronteira Brasil-Bolívia: A Interdição da Feira Bras-Bol em Corumbá-MS". Antropolítica. Revista Contemporânea de Antropologia, vol. 35, pp. 175-196.

. (2014b), “Táxis na Fronteira: Disputas pelo Espaço da Rua em Corumbá/Ladário (Brasil) Puerto Quijarro/Puerto Suarez (Bolívia)”, in A. R. Barbosa; B. Renoldi e M. Veríssimo (orgs.). (I)Legal: Etnografias em uma Fronteira Difusa. Vol. 1. Niterói, Editora da UFF, pp. 141-161.

. (2015), “Os Bolivianos em Corumbá-MS: Conflitos e Relações de Poder na Fronteira". Mana, vol. 21, pp. 35-63.

. (2016), “Os Filhos da Fronteira em Corumbá-MS: Os Estudantes de Origem Boliviana nas Margens da Nação", in J. Bahia e M. Santos (orgs.). Um Olhar sobre as Diferenças. A Interface entre Projetos Educativos e Migratórios. Vol. 1, São Leopoldo: Oikos, pp. 79-99.

DAS,Veena; POOLE, Deborah. (2008), “El Estado y sus Márgenes. Etnografías Comparadas". Cuadernos de Antropología Social, no 27, pp. 19-52.

DORFMAN, Adriana. (2013), “A Condição Fronteiriça Diante da Securitização das Fronteiras do Brasil”, in Nascimento, D. M. e Porto, J. L. R. (orgs). Fronteiras em Perspectiva Comparada e Temas de Defesa e Segurança da Amazônia. Belém, NAEA, vol. 1, pp. 96-124. 
ELIAS, Norbert. (1997), Os Alemães: A Luta pelo Poder e a Evolução do Habitus nos Séculos XIX e XX. Rio de Janeiro, Zahar.

FERREIRA, Andrey Cordeiro. (2009). "Políticas para Fronteira, História e Identidade: A Luta Simbólica nos Processos de Demarcação de Terras Indígenas Terena". Mana, vol. 15 , no 2 , pp. 377-410.

FOUCAULT, Michel. (2008), A Microfísica do Poder. Rio de Janeiro, Graal.

(2010), Em Defesa da Sociedade. São Paulo, Martins Fontes.

GRIMSON, Alejandro. (2003), La Nación en Sus Límites: Contrabandistas y Exiliados en la Frontera Argentina-Brasil. Barcelona, Gedisa.

LEACH, Edmund. (1995), Sistemas Políticos da Alta Birmânia: Um Estudo da Estrutura Social Kachin. São Paulo, EDUSP.

LOIS, María; CAIRO, Heriberto. (2011), “Introducción. Desfronterización y Refronterización en la Península Ibérica". Geopolítica(s). Revista de Estudios sobre Espacio y Poder, vol. 2, no 1 , pp. 11-22.

MACHADO DASILVA, Luiz Antonio. (2014), “A Experiência das UPPs: Uma Tomada de Posição". Dilemas: Revista de Estudos de Conflito e Controle Social, vol. 8, no 1, jan/fev/mar, pp. 7- 24.

Ministro da Defesa visita Corumbá e Ladário durante Operação “Ágata 11". (2016), Marinha do Brasil. Disponível em: <https:/ / www.marinha.mil.br/node/1496>.

NEVES, Alex J. et al. (orgs.). (2016), Segurança Pública nas Fronteiras: Diagnóstico Socioeconômico e Demográfico. Brasília, Ministério da Justiça e Cidadania e Secretaria Nacional de Segurança Pública.

OLIVAR, José Miguel Nieto.; CUNHA, Flávia Melo; ROSA, Patrícia Carvalho (2015), "Presenças e Mobilidades Transfronteiriças entre Brasil, Peru e Colômbia: O Caso da ‘Migração Peruana na Amazônia Brasileira'”. Tomo, no 26, jan/jun., pp. 123-163.

OLIVEIRA, Giovanni França. (2013), “O Policial de Fronteira e o Policial da Fronteira: Considerações sobre a Distinção de Pessoa e Indivíduo nas Práticas Policiais de Combate e Repressão no Varejo de Drogas em Corumbá na Fronteira com a Bolívia". Anais do XVI Congresso Brasileiro de Sociologia. Salvador, 10-13 de setembro, Universidade Federal da Bahia.

PALERMO, Luis Claudio (2015), “Notas sobre o Poder de Agência dos Atores Sociais em Anthropology in the Margins of the State". Revista Cadernos de Estudos Sociais e Politicos, vol. 4, no 8, jul-dez., pp. 57-86.

VALCUENDE DEL RÍO, José M.; CARDIA, Lais M. (2009), “Etnografia das Fronteiras Políticas e Sociais na Amazônia Ocidental: Brasil, Peru e Bolívia”. Scripta Nova. Revista Electrónica de Geografía y Ciencias Sociales. Universidad de Barcelona, vol. XIII, no 292, pp. 281-309.

VAN GENNEP, Arnold. (1978), Os Ritos de Passagem. Petrópolis, Vozes.

VAN HOUTUM, Henk e NAERSSEN, (2002), "Bordering, Ordering, Othering". Tijdschrift Voor Economischeen Sociale Geografie, vol. 93, no 2, pp. 125-136.

DADOS - Revista de Ciências Sociais, Rio de Janeiro, vol. 61, n² 2, 2018 


\section{Gustavo Villela Lima da Costa}

\section{Sítios eletrônicos consultados:}

http://www.ibge.gov.br

http:/ / www.defesa.gov.br/projetosweb/estrategia / arquivos/estrategia_defesa_nacional_portugues.pdf

http:/ / diarionline.com.br/index.php?s=noticia\&id $=83168$

http:/ / diarionline.com.br/index.php?s=noticia\&id=83168

http:/ / www.correiodecorumba.com.br/?s=noticia\&id=14084

http: / /www.corumba.ms.gov.br/noticias/em-encontro-com-presidente-evo-morales-prefeito-paulo-duarte-discute-temas-fronteiricos/1598

http:/ / perolanews.com.br/noticias/ corumba / corumba-apoia-acoes-na-fronteira-para-evitar-avanco-da-dengue

http:/ / www.corumba.ms.gov.br/noticias / corumba-programa-acoes-de-combate-a-dengue-na-bolivia/5032/

www.corumba.ms.gov.br/noticias / comunidade-boliviana-celebra-data-patria-com-ato-civico-e-cultural/16737/

http:/ / www.correiodecorumba.com.br/?s=noticia\&id=18728

http://www.corumba.ms.gov.br/noticias/corumba-recebe-operacao-de-guerra-contra-mosquito-aedes-aegypti/19381/ 


\section{RESUMO}

Governamentalidade e Soberania na Fronteira Brasil-Bolívia: Segurança Nacional e Saúde Pública como Dispositivos de Poder

Este artigo propõe uma análise da governamentalidade estatal fronteiriça, a partir de seus principais dispositivos de poder em ação: Segurança e Saúde, em que as esferas "públicas" e "nacionais" se tornam cada vez mais imbricadas. Essa gestão estatal se baseia na visão da fronteira como limite, como área de perigo e contágio, e é legitimada, localmente, por um "ethos" militar construído ao longo da história de Corumbá-MS. Na primeira parte do artigo, observaremos etnograficamente a atuação dessa soberania territorial e política do Estado, com foco na mudança do papel das forças armadas, que atuam cada vez mais com o papel de polícia num processo, em curso, de reconfiguração das políticas de segurança na fronteira. Na segunda seção do texto, articularemos as políticas de saúde na região com esse processo de securitização, observando desde as operações de vacinação, passando por barreiras sanitárias, chegando até a maternidade municipal, no caso do atendimento às gestantes bolivianas. Esta pesquisa nos permite compreender distintas situações de conflito em torno dos paradigmas estatais e da ubiquidade dos valores nacionais que tendem não apenas a recusar a alteridade na fronteira, mas também, a (re)produzi-la de modo negativo.

Palavras-chave: Fronteira, Governamentalidade, Segurança Nacional, Biopolítica, Saúde Pública

\section{ABSTRACT \\ Governmentality and Sovereignty in the Brazil-Bolivia Border: National Security and Public Health as Devices of Power}

This article proposes an analysis of the governmental statehood of the border, from its main mechanisms of power in action: Security and Health, in which the "public" and "national" spheres become increasingly imbricated. This state management is based on the border thought as a limit, as an area of danger and contagion, and is legitimated, locally, by a military ethos built throughout the history of Corumbá-MS. In the first part of the article, we will observe ethnographically the performance of this territorial and political sovereignty of the State, with a focus on the changing role of the armed forces, who increasingly act with as police in an ongoing process of reconfiguration of security policies in the border. In the second section of the text, we will articulate the health policies in the region with this process of securitization, 


\section{Gustavo Villela Lima da Costa}

from vaccination operations, through sanitary barriers, to the municipal maternity, in the case of care for Bolivian pregnant women. This research allows us to understand different situations of conflict around the state paradigms and the ubiquity of national values ??that tend not only to refuse otherness at the border, but also to (re) produce it in a negative way.

Keywords: Frontier, Governmentality, National Security, Biopolitics, Public Health

\section{RESUMEN}

Gubernamentalidad y Soberanía en la Frontera Brasil-Bolivia: Seguridad Nacional y Salud Pública como Dispositivos de Poder

Este artículo propone un análisis de la gubernamentalidad estatal fronteriza, a partir de sus principales dispositivos de poder en acción: Seguridad y Salud, en que las esferas "públicas" y "nacionales" se vuelven cada vez más imbricadas. Esta gestión estatal se basa en la visión de la frontera como límite, como área de peligro y contagio, y es legitimada, localmente, por un "ethos" militar construido a lo largo de la historia de Corumbá-MS. En la primera parte del artículo, observaremos etnográficamente la actuación de esa soberanía territorial y política del Estado, con foco en el cambio del papel de las fuerzas armadas, que actúan cada vez más con el papel de policía en un proceso, en curso, de reconfiguración de las políticas de seguridad en la frontera. En la segunda sección del texto, articularemos las políticas de salud en la región con ese proceso de securitización, observando desde las operaciones de vacunación, pasando por barreras sanitarias, llegando hasta la maternidad municipal, en el caso de la atención a las gestantes bolivianas. Esta investigación nos permite comprender distintas situaciones de conflicto en torno a los paradigmas estatales y de la ubicuidad de los valores nacionales que tienden no sólo a rechazar la alteridad en la frontera, sino también a (re) producirla de modo negativo.

Palabras clave: Frontera, Gobernabilidad, Seguridad Nacional, Biopolítica, Salud Pública 